\title{
The Experience of Relations in Persons with Dementia: A Systematic Meta-Synthesis
}

\author{
Siren Eriksen ${ }^{a}$ Anne-Sofie Helvik ${ }^{a, c}$ Lene Kristin Juvet ${ }^{b}, d$ \\ Kirsti Skovdahl $^{b}$ Linn Hege Førsund ${ }^{b}$ Ellen Karine Grov ${ }^{e}$ \\ ${ }^{a}$ Norwegian National Advisory Unit on Ageing and Health, Tønsberg, ${ }^{b}$ Institute of Nursing \\ Science, Faculty of Health and Social Work, University College of Southeast Norway, \\ Drammen, ' Department of Public Health and General Practice, Norwegian University of \\ Science and Technology, Trondheim, dThe Norwegian Knowledge Centre for the Health \\ Services, and ${ }^{e}$ Department of Nursing and Health Promotion, Faculty of Health Sciences, \\ Oslo and Akershus University College of Applied Sciences, Oslo, Norway
}

\author{
Keywords \\ Dementia · Meta-synthesis · Interviews · Lived relations · Life-world perspective · Person's \\ experiences
}

\begin{abstract}
Background: Dementia influences a person's experience of social relationships, as described in several studies. In this systematic meta-synthesis of qualitative studies, we aim to interpret and synthesize the experiences of persons with dementias and their relations with others. Summary: Living with dementia changes life, leading to new social roles and different social statuses. Persons with dementia experience being disconnected and dependent on others, feeling like being a burden, and being a person who is treated in paternalistic ways. Family, friends and others with dementia might play significant roles in their ability to maintain a meaningful life. Key Messages: Three categories emerged from the data, change in life, change in relations, and maintenance of meaningful aspects in life; these categories are intertwined and essential in sustaining a lifeline for persons with dementia. The comprehensive meaning of the material is understood as the expression: Living a meaningful life in relational changes.
\end{abstract}

(C) 2016 S. Karger AG, Basel

\section{Introduction}

Strauss [1] has stated that to each and every single person there is nothing general about life - life is in the details. From this perspective, lived experience and lived understanding of illness and context are important aspects of healthcare.

The psychosocial dimension often influences a person's health from an overall perspective. House et al. [2] showed that good, robust social relationships have as much of an impact on 
Eriksen et al.: The Experience of Relations in Persons with Dementia: A Systematic Meta-Synthesis

physical health and length of life as other lifestyle-related components. Crooks et al. [3] found that larger social networks have a protective influence on cognitive function among elderly women. Relationships will influence biological, psychological, and social mechanisms [4, 5]. It is not only being involved in social relationships or the size of our network that counts but also how a person experiences the social relations that are of great importance. Individuals who experience positive support from their family and friends describe their life as more meaningful and valuable than others [6].

Several studies have described how dementia influences a person's experience of psychosocial aspects. In one meta-synthesis of dignity in dementia care, Tranvåg et al. [7] stated that worthiness and sense of self are particularly important for persons with dementia (PWD). Steeman et al. [8] reviewed qualitative studies of early-stage dementia and found that individuals living with dementia experience threatened feelings of security, autonomy and being a meaningful member of society. In the systematic review of qualitative studies by Strech et al. [9], social and content-dependent aspects were emphasized as important ethical issues in dementia care. In a qualitative study of the perspective of anxiety in dementia, Qazi et al. [10] stated that surroundings and relations to others are important aspects of the development of anxiety in this group. Furthermore, 2 qualitative studies on ethics by Heggestad et al. [11] and Tranvåg et al. [12] highlighted that a lack of freedom and the feeling of not being confirmed and respected as an autonomous person might threaten personal dignity in PWD; moreover, relational interactions will preserve dignity for the same group of persons.

Several single studies have explored perspectives of how lived relations are experienced by PWD, for example how PWD hold on to their roles in social relationships in which they experience being valuable to others [13], the importance of deep, long-term friendships that still remain [14], and how PWD adjust to their relational situation of feeling incompetent, but still loved [15]. Additionally, one study focused on how PWD feel useless and a burden to their family and therefore avoid sharing their thoughts and worries in order to protect the family and themselves [16]. Considering how important relationships with others are for health and well-being, the challenges faced by PWD, and the help and support PWD require, there is a need for a systematic review that synthesizes the knowledge on this particular perspective.

\section{Theoretical Frame}

Lived relations with others are social and cultural phenomena that cannot be separated from the life-world perspective [17]. This meta-synthesis is guided by the theoretical frame of the Dutch philosopher Max van Manen [18], who stated that the grounding level of human existence has fundamental and thematic structures. The structures of the human life-world, as experienced in everyday situations and relations differ from human to human and during a day or a period. van Manen identified four fundamental existential themes of the life-world to describe and constitute the complexity of the life-world: (1) lived body, (2) lived space, (3) lived time, and (4) lived others.

According to the lived experience of the body, van Manen postulated the position of the body by describing human beings as living in the world with the body, and living and being in relation with others through the body [18]. The experience of lived space is described as the "felt space." The experience of space is often pre-verbal, in contrast to mathematical space or the length, depth, or height dimensions of space. The experience of lived time covers the experience of perceived time as opposed to clock time or objective time. Lived time describes our temporal way of being in the world. The three dimensions of past, present, and future constitute the horizons of a temporal landscape.

According to the fourth existential describing lived relation to other persons, lived other, we share an "interpersonal space" with the people around us. When we meet other persons, we have the opportunity to develop a conversational relationship, which allows us to tran- 
Eriksen et al.: The Experience of Relations in Persons with Dementia: A Systematic Meta-Synthesis

scend ourselves. van Manen highlights that within the experience of others, human beings search for a sense of purpose in life, meaningfulness and grounds for living.

The existentials may be reflected upon separately, but they are interwoven and only as a whole will they constitute the life-world. van Manen claimed that a changed experience in one of the four life-world existentials would influence the others and therefore the experience of the life-world as a whole [18]. However, in this systematic meta-synthesis, we will emphasize the perspective of lived others.

\section{The Review}

\section{Aim}

The aim of this systematic meta-synthesis was to interpret and synthesize PWD's experiences of lived relations with others.

Design

An interpretative qualitative meta-synthesis was conducted, inspired by the approaches and methods described by Paterson et al. [19] and Zimmer [20].

\section{Search Method}

Literature Search and Selection

We conducted a systematic, computerized search of MEDLINE, Embase, CINAHL Complete, PsycINFO and AgeLine. The search strategy combined MeSH terms and text words for different types of dementia with different descriptions of experience. The combinations of search terms are shown in Table 1. Studies were restricted to peer-reviewed research articles, qualitative studies with best specificity, written in the English language and published between January 2004 and May 2016. The searches resulted in 1,309 articles, of which 131 were identified as eligible. A flow chart for the selection of articles is presented in Figure 1.

Two pairs of authors (E.K.G. and S.E./L.K.J. and S.E.) independently reviewed the titles, abstracts, and, in some cases, the full articles of all the identified studies to ensure that there were always 2 authors selecting the articles in terms of screening, eligibility and inclusion, according to the PRISMA standard of systematic reviews [21]. Disagreement was resolved by discussion, and, if necessary, by consulting one of the other authors. Studies were included if they met the following criteria: (1) sample of PWD only; (2) qualitative interview as a research method; (3) persons' with dementia voices should be explicit; and (4) describing experiences of lived relations with other persons. Studies were excluded according to the following criteria: (1) mixed sample or uncertainty due to dementia (i.e., probable or possible dementia), and (2) studies of a certain intervention.

\section{Assessment of the Quality of the Studies}

One hundred and thirty-one full-text articles were read and reviewed according to the CASP criteria for qualitative studies (http://www.casp-uk.net/\#|casp-tools-checklists/ c18f8). The quality of all studies was assessed by pairs of authors (L.K.J. and E.K.G./L.H.F. and K.S./A.-S.H. and S.E.). Disagreement was resolved by discussion, and, if necessary, by consulting one of the other authors. The CASP appraisal tool includes the following 9 criteria: (1) clear statement of aims; (2) appropriate choice of method; (3) appropriate research design; (4) congruence between recruitment strategy, aims and research; (5) data collection method addresses the research issue; (6) relationship between researcher and participant was considered; (7) ethical issues were considered; (8) process of data analysis was sufficiently rigorous; and (9) clear statement of the findings. Each criterion was given an equal weight 
Eriksen et al.: The Experience of Relations in Persons with Dementia: A Systematic

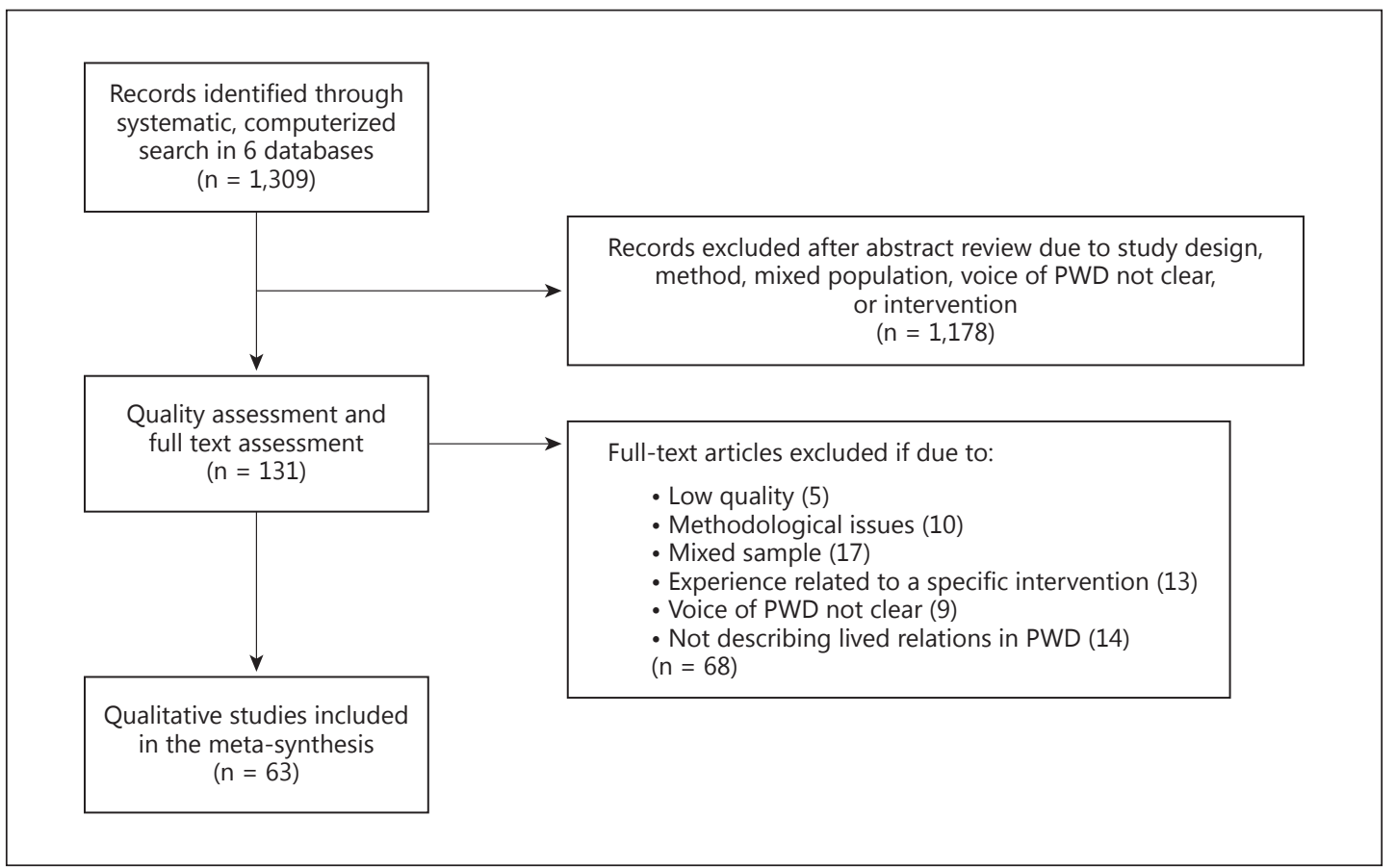

Fig. 1. Flow chart of the literature search.

Table 1. Search terms

\begin{tabular}{|c|c|}
\hline Population & Experience \\
\hline $\begin{array}{l}\text { MeSH terms: } \\
\text { Dementia (CINAHL, Embase, MEDLINE, PsycINFO) } \\
\text { Dementia, presenile (CINAHL, Embase, MEDLINE, PsycINFO) } \\
\text { Dementia, senile (CINAHL, Embase, MEDLINE, PsycINFO) } \\
\text { Alzheimer's disease (CINAHL, Embase, MEDLINE, PsycINFO) } \\
\text { Dementia, multi-infarct (CINAHL, Embase, MEDLINE, PsycINFO) } \\
\text { Lewy body disease (CINAHL, Embase, MEDLINE, PsycINFO) } \\
\text { Dementia, vascular (CINAHL, MEDLINE, PsycINFO) } \\
\text { Dementia, frontotemporal (Embase) } \\
\text { Text words: } \\
\text { Dement* } \\
\text { Presenile dement* } \\
\text { Senile dement* } \\
\text { Alzheimer* } \\
\text { Multi-infarct dement* } \\
\text { Lewy body dement* } \\
\text { Vascular dement* } \\
\text { Frontotemporal dement* } \\
\text { All words combined with OR }\end{array}$ & $\begin{array}{l}\text { MeSH terms: } \\
\text { Life experience (CINAHL, PsycINFO) } \\
\text { Experience (Embase) } \\
\text { Personal experience (Embase) } \\
\text { Text words: } \\
\quad \text { Personal experience* } \\
\text { Experience* } \\
\text { Lived experience* } \\
\text { Life experience* } \\
\text { Patient experience* } \\
\text { Subjective experience* } \\
\text { First-person } \\
\text { ** } \\
\text { All words combined with OR }\end{array}$ \\
\hline
\end{tabular}


Eriksen et al.: The Experience of Relations in Persons with Dementia: A Systematic

Table 2. Quality assessment of studies included

First author [Ref.], year

Criteria $^{a}$

Total/9 Quality

\begin{tabular}{lllllllll}
\hline 1 & 2 & 3 & 4 & 5 & 6 & 7 & 8 & 9
\end{tabular}

Aminzadeh [36], 2009

Aminzadeh [37], 2010

Atta-Konadu [38], 2011

Barrett [39], 2015

Bronner [40], 2016

Chaplin [41], 2016

Clare [42], 2008

Clemerson [43], 2014

Dalby [44], 2012

Derksen [13], 2006

Fleming [45], 2015

Frazer [16], 2012

Genoe [47], 2010

Genoe [48], 2012

Genoe [49], 2014

Gill [50], 2011

Gilmour [51], 2005

Goodman [52], 2013

Hain [53], 2014

Harman [54], 2006

Harmer [55], 2008

Harris [56], 2012

Harris [14], 2013

Hedman [57], 2013

Hedman [58], 2016

Heggestad [11], 2013

Hellström [59], 2015

Hulko [60], 2009

Hyden [61], 2015

Johannessen [62], 2011

Johannessen [63], 2014

Karlsson [64], 2014

Keller [65], 2010

Langdon [66], 2007

Lawrence [67], 2009

Lee [68], 2014

MacKinlay [69], 2009

MacRae [70], 2011

Mazaheri [71], 2013

Mazaheri [15], 2014

Merrick [72], 2016

Mok [16], 2007

Molyneaux [73], 2012

Moyle [74], 2011

Mushi [75], 2014

Nowell [76], 2013

Nygård [77], 2008

Öman [78], 2005

$+++++++++\quad 9 \quad$ high

high

moderate

moderate

moderate

moderate

high

high

high

moderate

high

high

high

high

high

high

high

moderate

moderate

Pesonen [79], 2013

Phinney [80], 2006

Pipon-Young [81], 2012

Roach [82], 2016

Rostad [83], 2013

Samsi [84], 2013

Sixsmith [85], 2007

$\begin{array}{lllllllllll}+ & + & + & + & + & + & + & + & + & 9 \\ + & + & + & + & + & + & + & + & + & 9 \\ + & + & + & + & + & - & + & + & + & 8\end{array}$

$+\quad+\quad+\quad-\quad+\quad-\quad+\quad+\quad+$

9

high

high

high

high

high

high

high

moderate

high

moderate

moderate

moderate

high

moderate

high

high

moderate

high

high

high

high

moderate moderate

high

moderate

moderate

high

moderate

moderate

high

moderate

high

moderate

moderate

moderate

moderate 
Table 2 (continued)

\begin{tabular}{|c|c|c|c|c|c|c|c|c|c|c|c|}
\hline \multirow[t]{2}{*}{ First author [Ref.], year } & \multicolumn{9}{|c|}{ Criteria $^{a}$} & \multirow[t]{2}{*}{ Total/9 } & \multirow[t]{2}{*}{ Quality } \\
\hline & 1 & 2 & 3 & 4 & 5 & 6 & 7 & 8 & 9 & & \\
\hline Svanström [86], 2015 & + & + & + & + & + & - & + & + & + & 8 & moderate \\
\hline Tak [87], 2015 & + & + & + & + & + & - & + & + & + & 8 & moderate \\
\hline Toms [88], 2015 & + & + & + & + & + & - & + & + & + & 8 & moderate \\
\hline Van Zadelhoff [89], 2011 & + & + & + & + & + & - & + & + & + & 8 & moderate \\
\hline Vernooij-Dassen [90], 2006 & + & + & + & + & + & - & - & + & + & 7 & moderate \\
\hline Vikström [91], 2008 & + & + & + & + & + & - & - & + & + & 7 & moderate \\
\hline Weaks [32], 2015 & + & + & + & + & + & + & + & + & + & 9 & high \\
\hline Wolverson [92], 2010 & + & + & + & + & + & + & - & + & + & 8 & moderate \\
\hline
\end{tabular}

9, high quality, 7-8, moderate quality, 6 or less, low quality. ${ }^{\text {a } C A S P}$ criteria: 1 , Clear research statement; 2, Qualitative methodology; 3, Research question appropriate; 4, Recruitment strategy; 5, Data collection; 6 , Relationship researcher-participants described adequately; 7, Ethical considerations; 8, Data analysis; 9 , Clear statements of findings.

(i.e., 1 point) for a maximum score of 9 for each quality assessment per article. A score of 9 was considered high methodological quality, whereas 7-8 points was considered moderate quality; see Table 2. Only studies with moderate (13) and high quality (50) were included in this review. Five studies were excluded due to low quality (scores $<7$ ). This meta-synthesis is based on 63 articles.

The meta-synthesis includes interviews with 874 PWD. In 13 of the studies, the participants were living in nursing homes or other care facilities. In 55 of the studies, individual interviews with PWD were the main data collected. Eight studies performed interviews with dyads or pairs, and 4 studies performed focus group interviews. The included studies are presented in Table 3, along with the information described in the different papers (see Table 3).

\section{Data Abstraction and Synthesis}

The abstraction process was conducted according to the principles of interpretative synthesis [22] by focusing on the development of concepts based on the data from primary studies and further developing and specifying theories that integrated those concepts [23]. The analysis was inspired by the analytic approach of Graneheim and Lundman [24]. The analytic process comprised 5 steps:

In the first step, pairs of authors (L.K.J. and E.K.G./L.H.F. and K.S./A.-S.H. and S.E.) read and reread one-third of the papers each. The results from each paper describing lived relations for PWD were extracted as direct citations into a form created for further analysis: "meaning units," according to Graneheim and Lundman [24].

Three of the authors (A.-S.H., E.K.G., and S.E.) conducted the further analysis of the descriptions of lived relations for PWD.

In the second step, meaning units were further condensed and labelled with codes to organize the material. The third step involved comparing codes, identifying similarities and differences, and structuring the codes into subcategories. The 8 subcategories identified through this process were ultimately gathered into 3 categories in the fourth step to describe the manifest meaning of the material (Table 4). In the fifth step, the comprehensive understanding phase, the categories were summarized and reflected upon to reach a presentation of the text as one overall, latent theme. 
Dementia

Cognitive Disorders

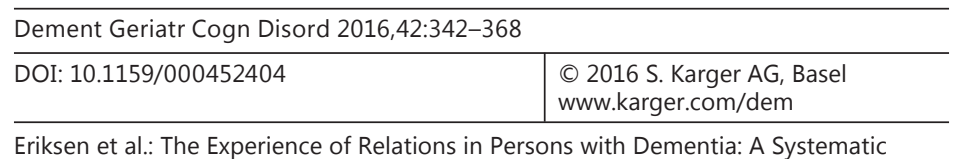

Eriksen et al.: The Experience of Relations in Persons with Dementia: A Systematic Meta-Synthesis

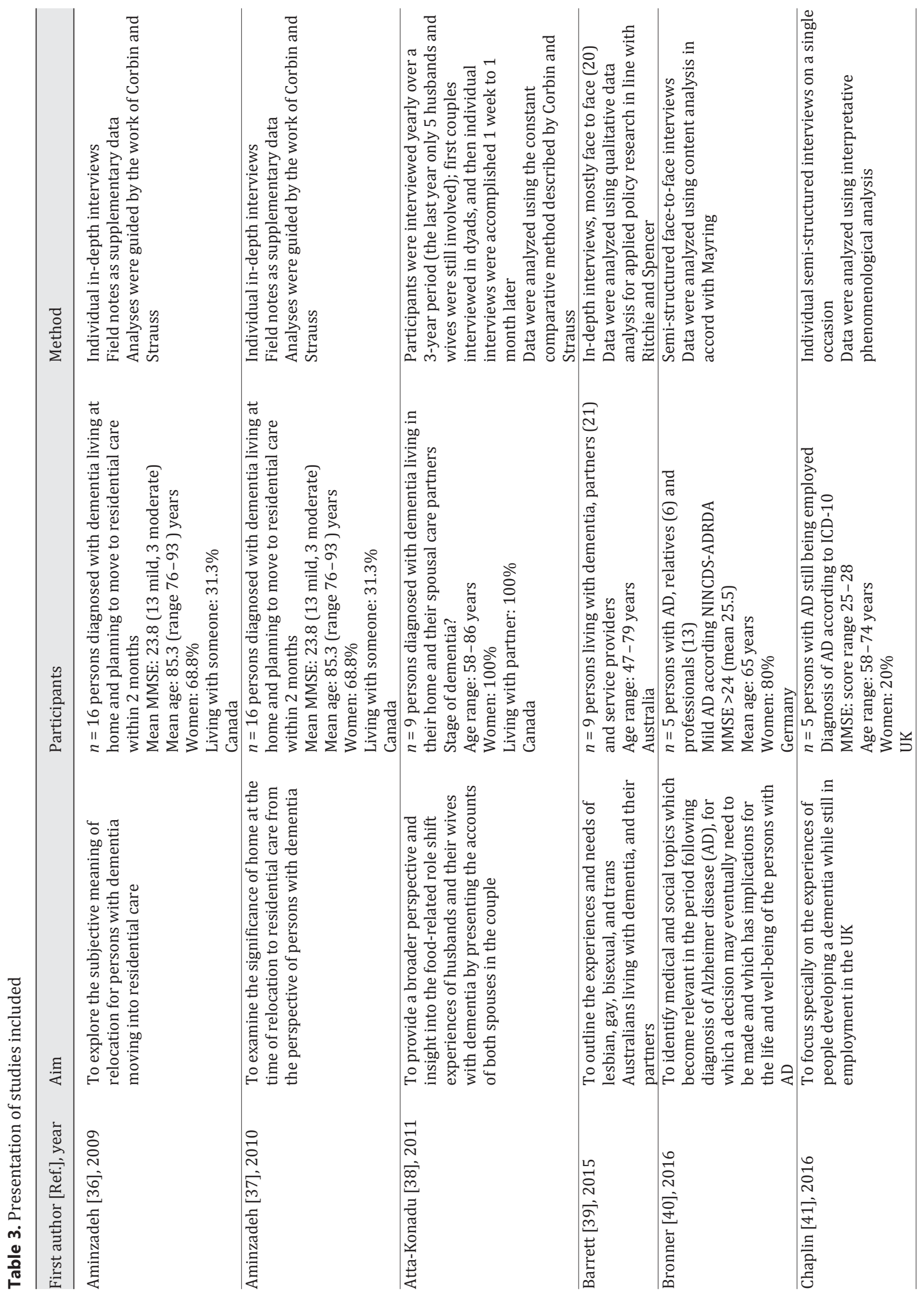


Dementia

and Geriatric
Cognitive Disorders
Dement Geriatr Cogn Disord 2016,42:342-368

DOI: $10.1159 / 000452404$

2016 S. Karger AG, Basel

Eriksen et al.: The Experience of Relations in Persons with Dementia: A Systematic Meta-Synthesis

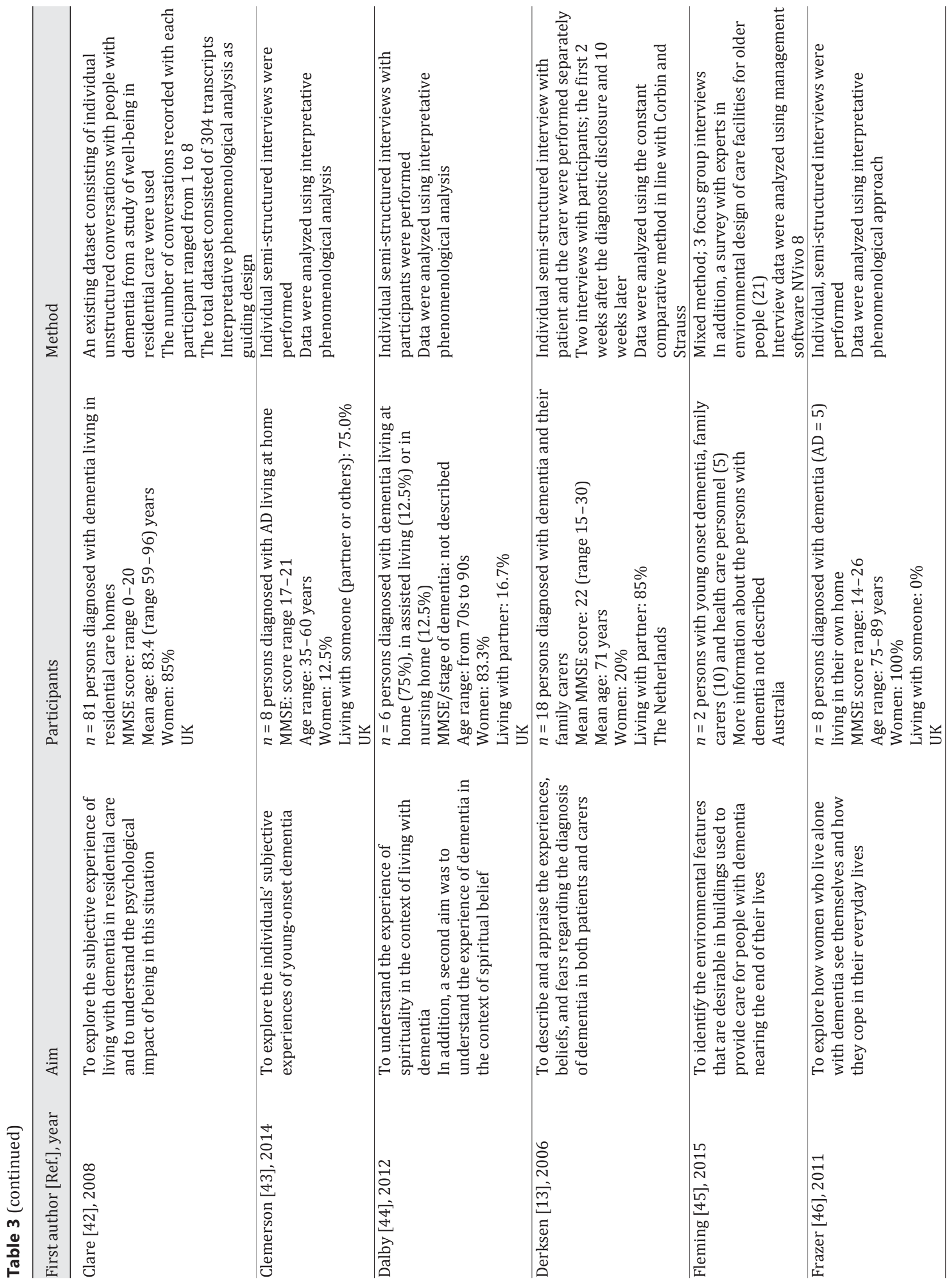


Dementia

Cognitive Disorders
Dement Geriatr Cogn Disord 2016,42:342-368

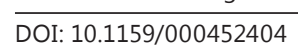

Eriksen et al.: The Experience of Relations in Persons with Dementia: A Systematic Meta-Synthesis

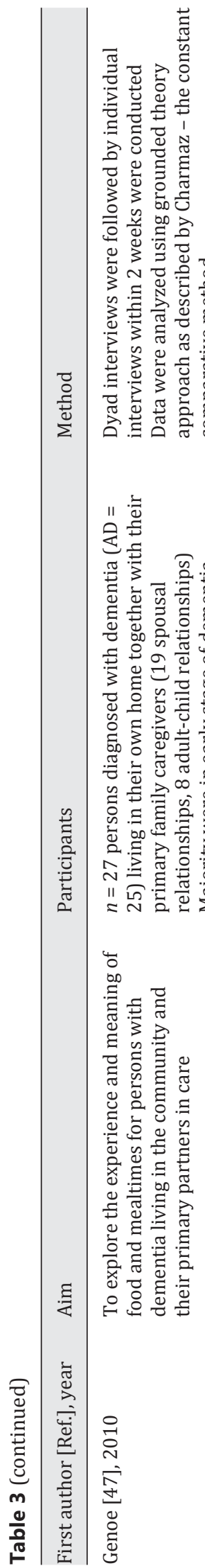

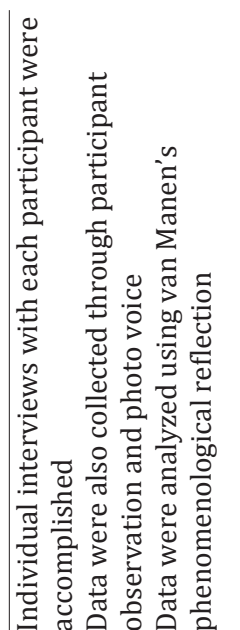

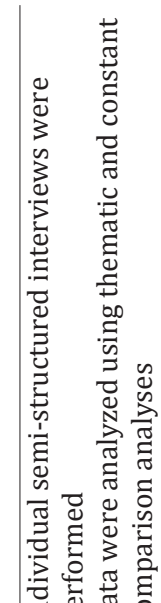

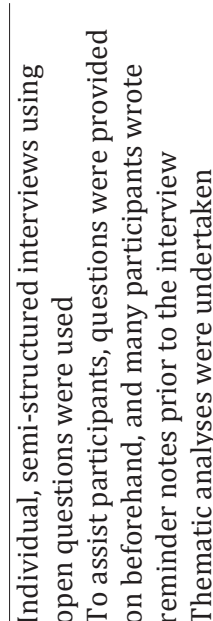

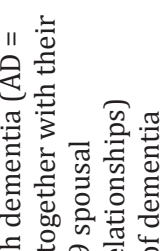

त 유 की

䇈过

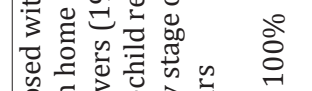

कू

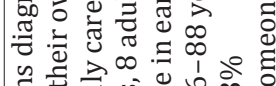
至

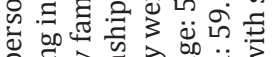
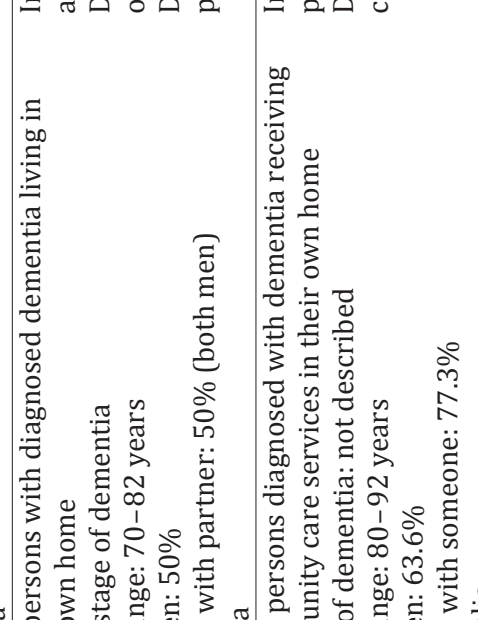

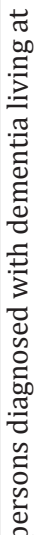
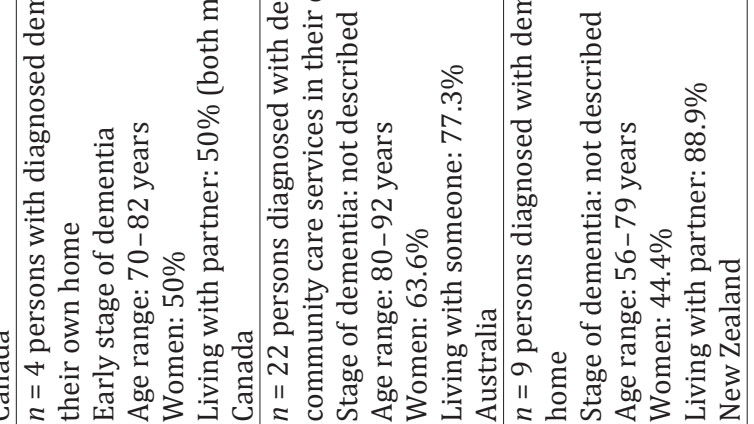

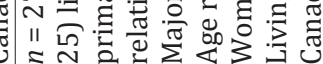
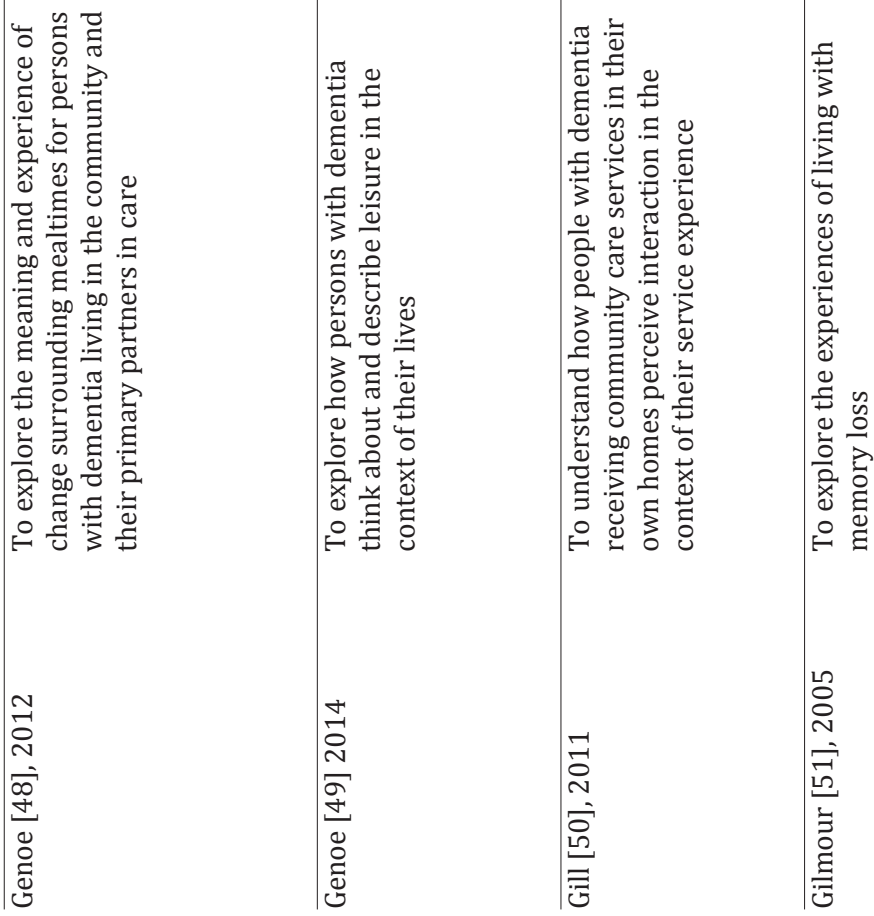
Dementia

Cognitive Disorders
Dement Geriatr Cogn Disord 2016,42:342-368

DOI: $10.1159 / 000452404$

www.karger.com/dem

Eriksen et al.: The Experience of Relations in Persons with Dementia: A Systematic Meta-Synthesis

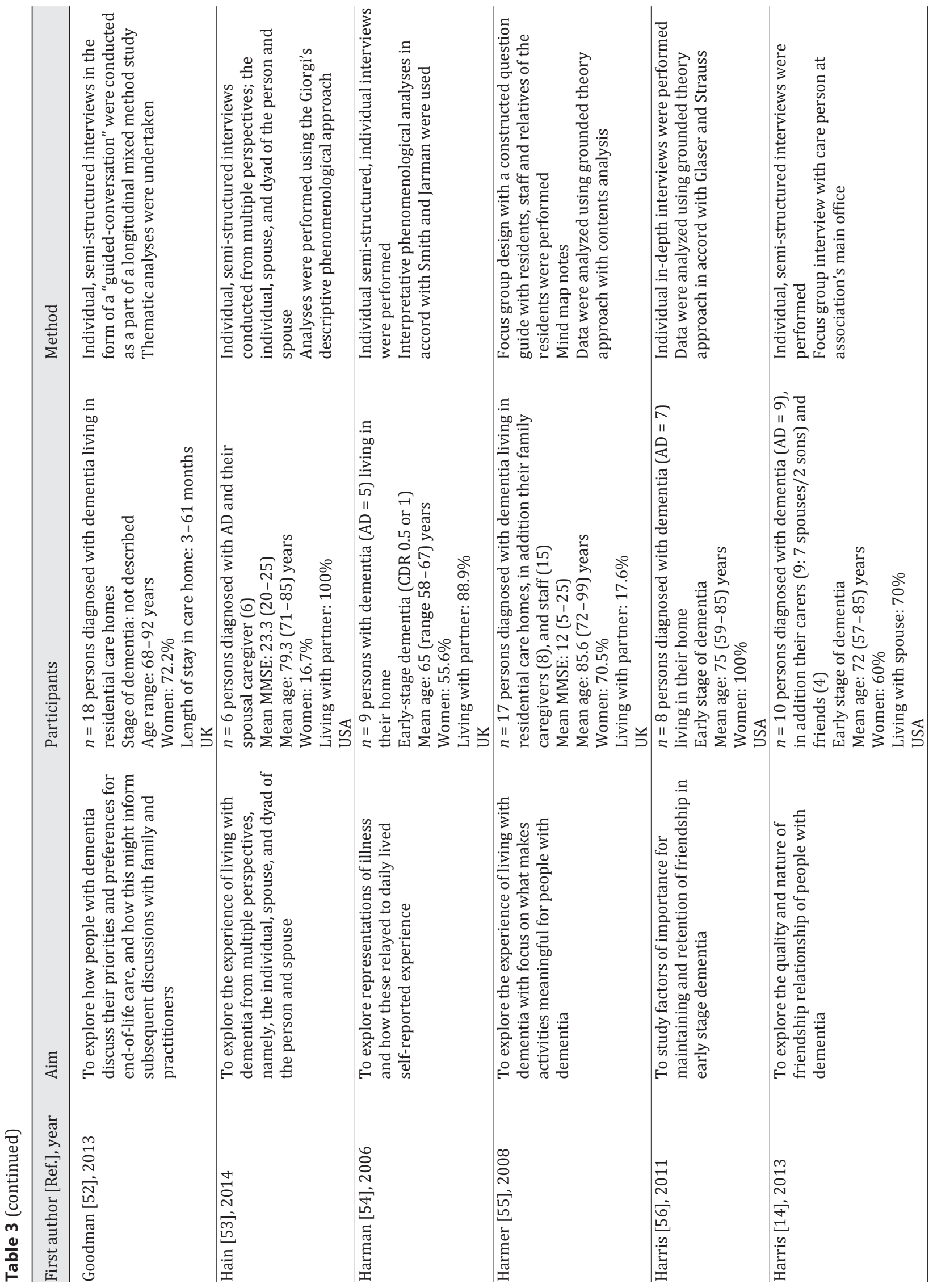


Dementia

Cognitive Disorders
Dement Geriatr Cogn Disord 2016,42:342-368

DOI: $10.1159 / 000452404$

Eriksen et al.: The Experience of Relations in Persons with Dementia: A Systematic Meta-Synthesis

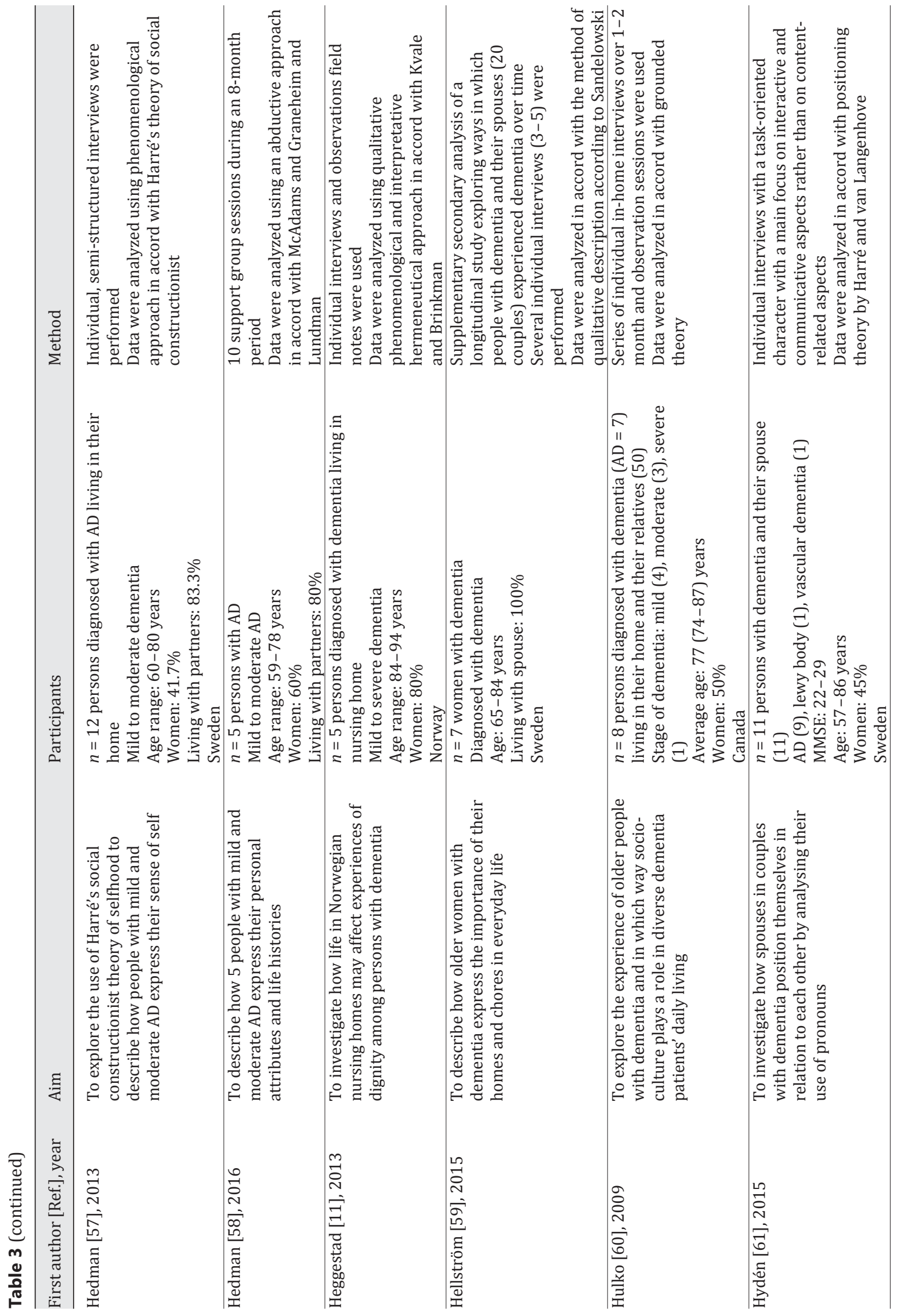


Dementia

Cognitive Disorders
Dement Geriatr Cogn Disord 2016,42:342-368

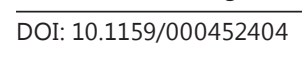

2016 S. Karger AG, Basel
ww.karger.com/dem

Eriksen et al.: The Experience of Relations in Persons with Dementia: A Systematic Meta-Synthesis

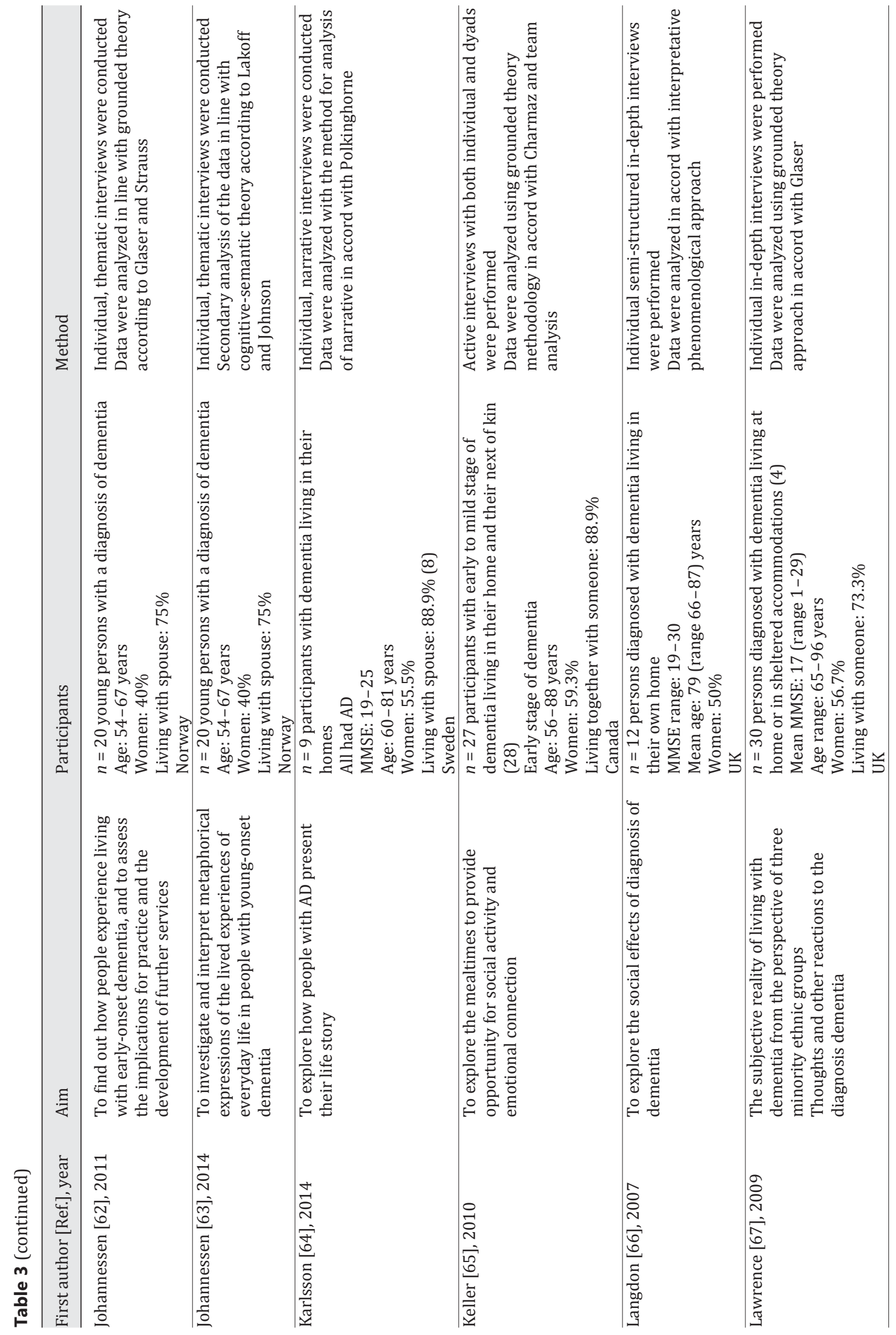


Dementia

Cognitive Disorders
Dement Geriatr Cogn Disord 2016,42:342-368

DOI: 10.1159/000452404

C 2016 S. Karger AG, Basel

www.karger.com/dem

Eriksen et al.: The Experience of Relations in Persons with Dementia: A Systematic Meta-Synthesis

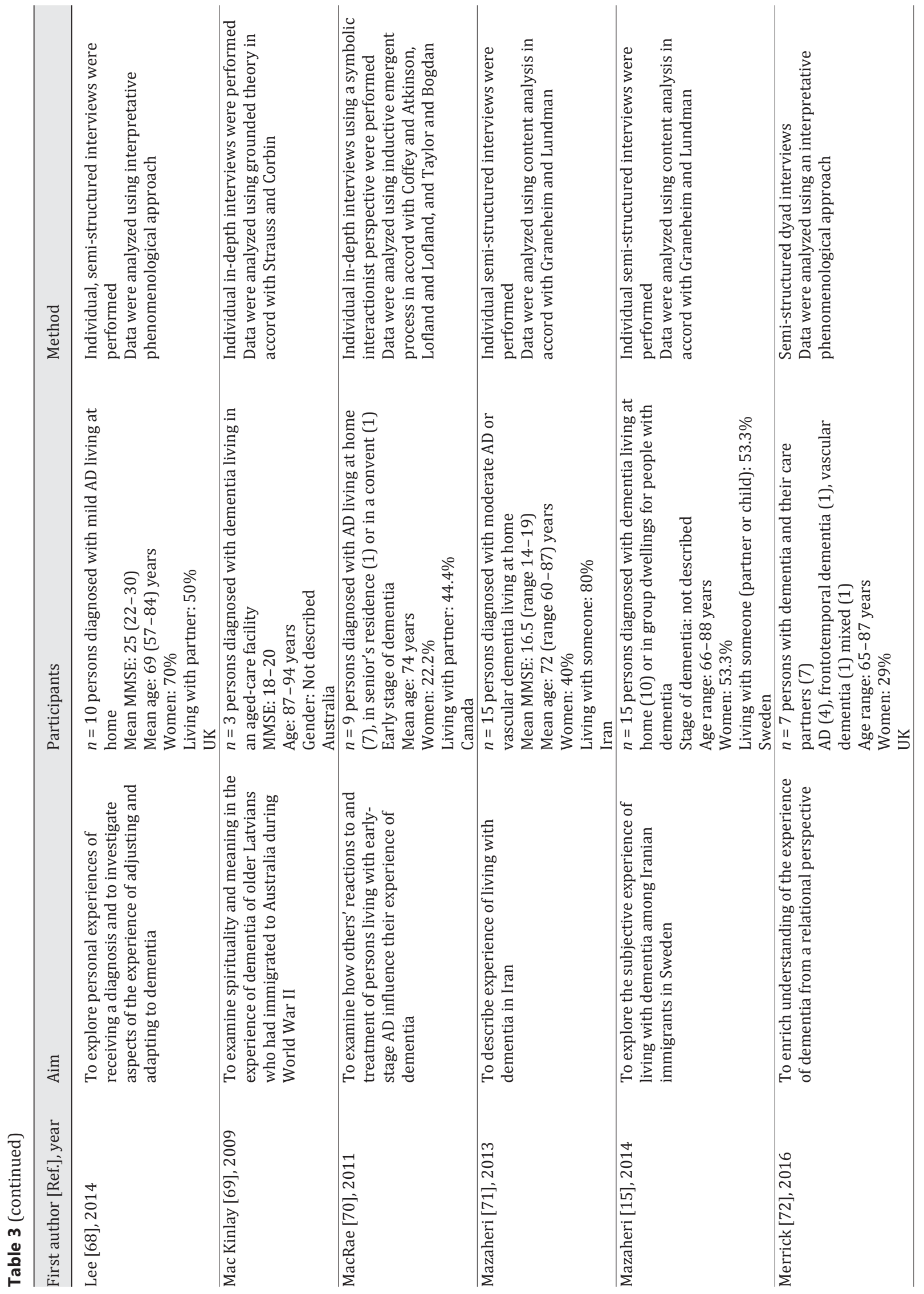


Dementia

Cognitive Disorders
Dement Geriatr Cogn Disord 2016,42:342-368

DOI: $10.1159 / 000452404$

Eriksen et al.: The Experience of Relations in Persons with Dementia: A Systematic Meta-Synthesis

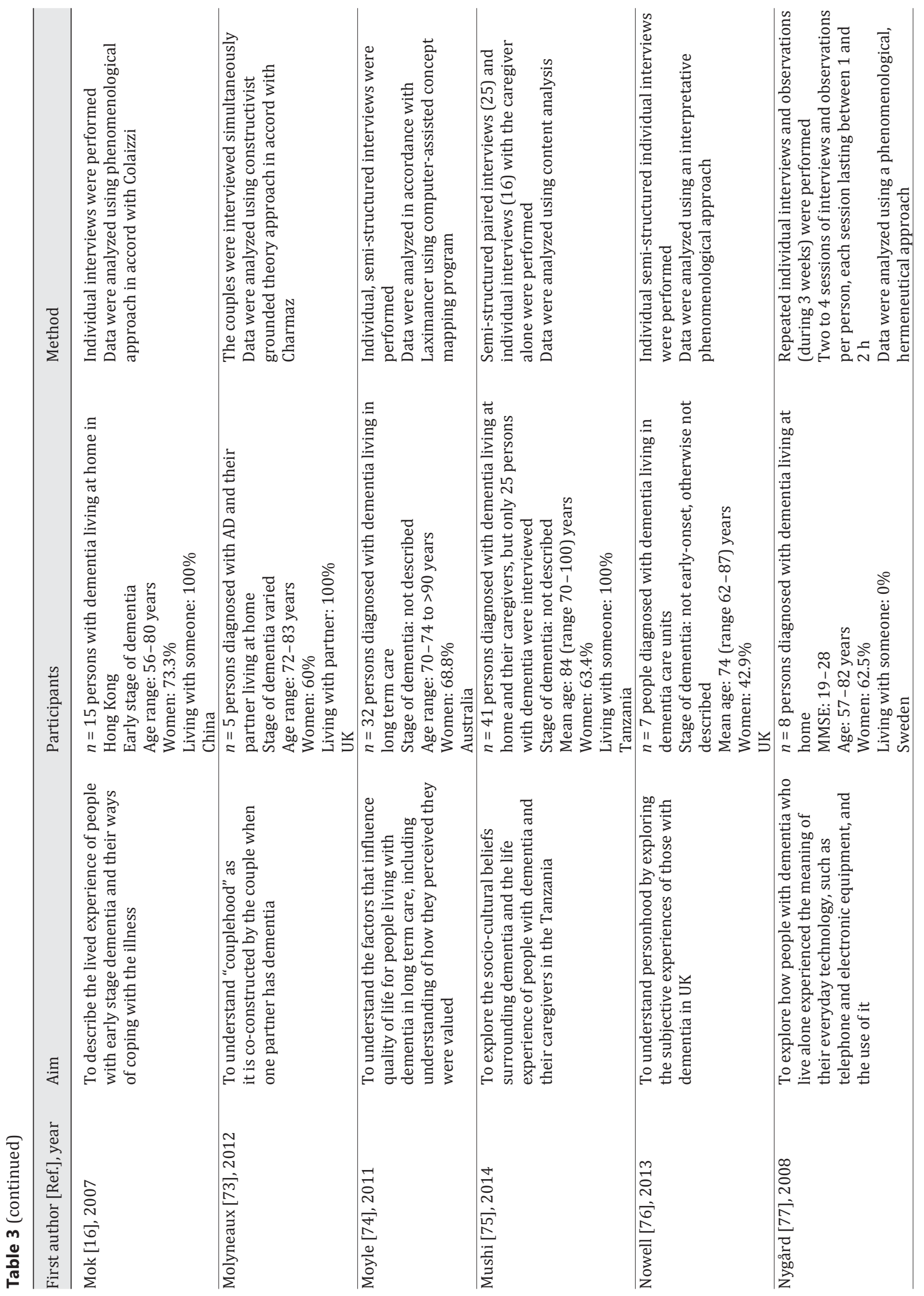


Dementia

Cognitive Disorders
Dement Geriatr Cogn Disord 2016,42:342-368

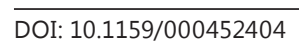

Eriksen et al.: The Experience of Relations in Persons with Dementia: A Systematic Meta-Synthesis

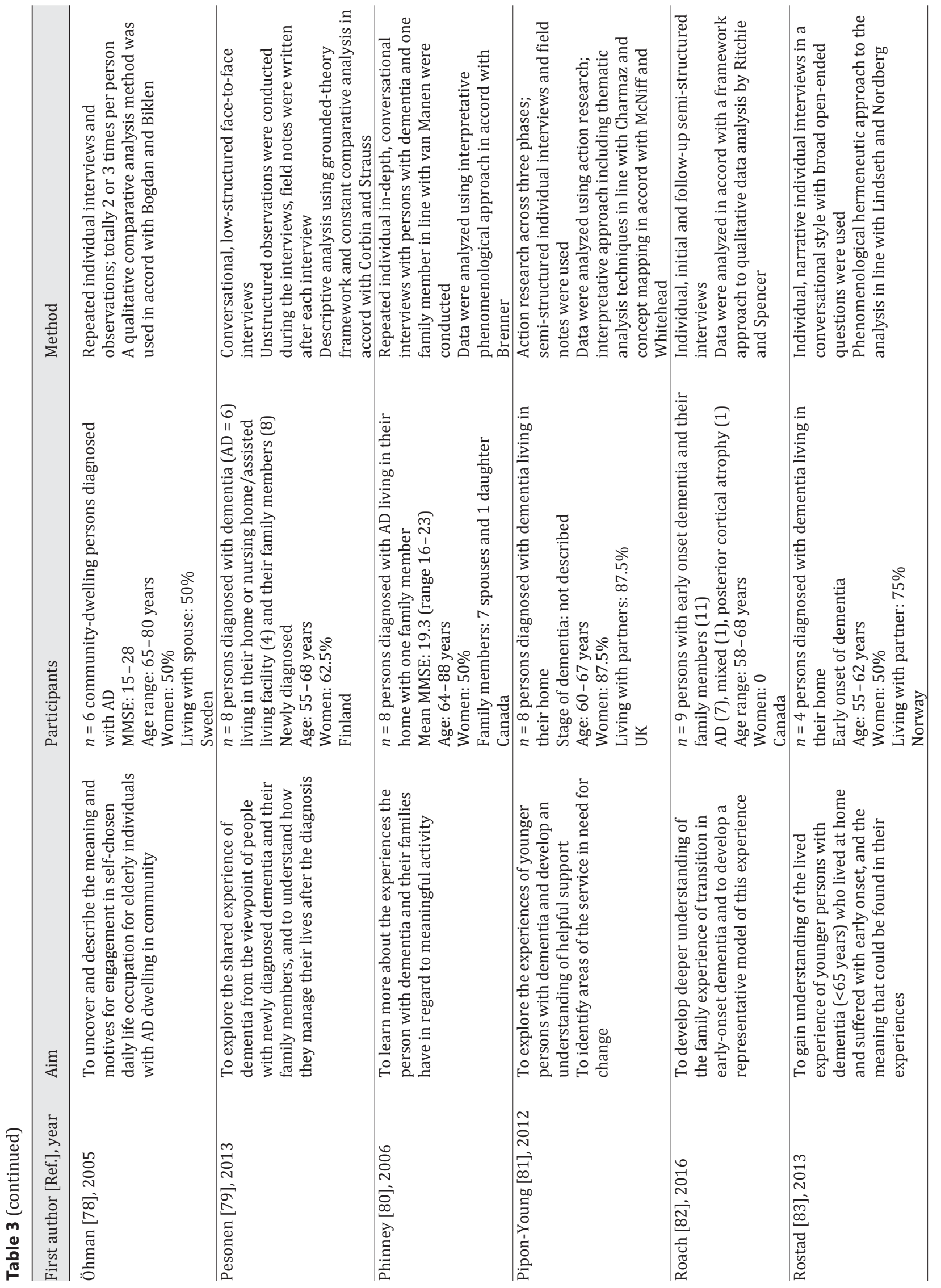


Dementia

Cognitive Disorders
Dement Geriatr Cogn Disord 2016,42:342-368

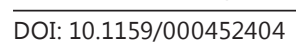

Eriksen et al.: The Experience of Relations in Persons with Dementia: A Systematic Meta-Synthesis

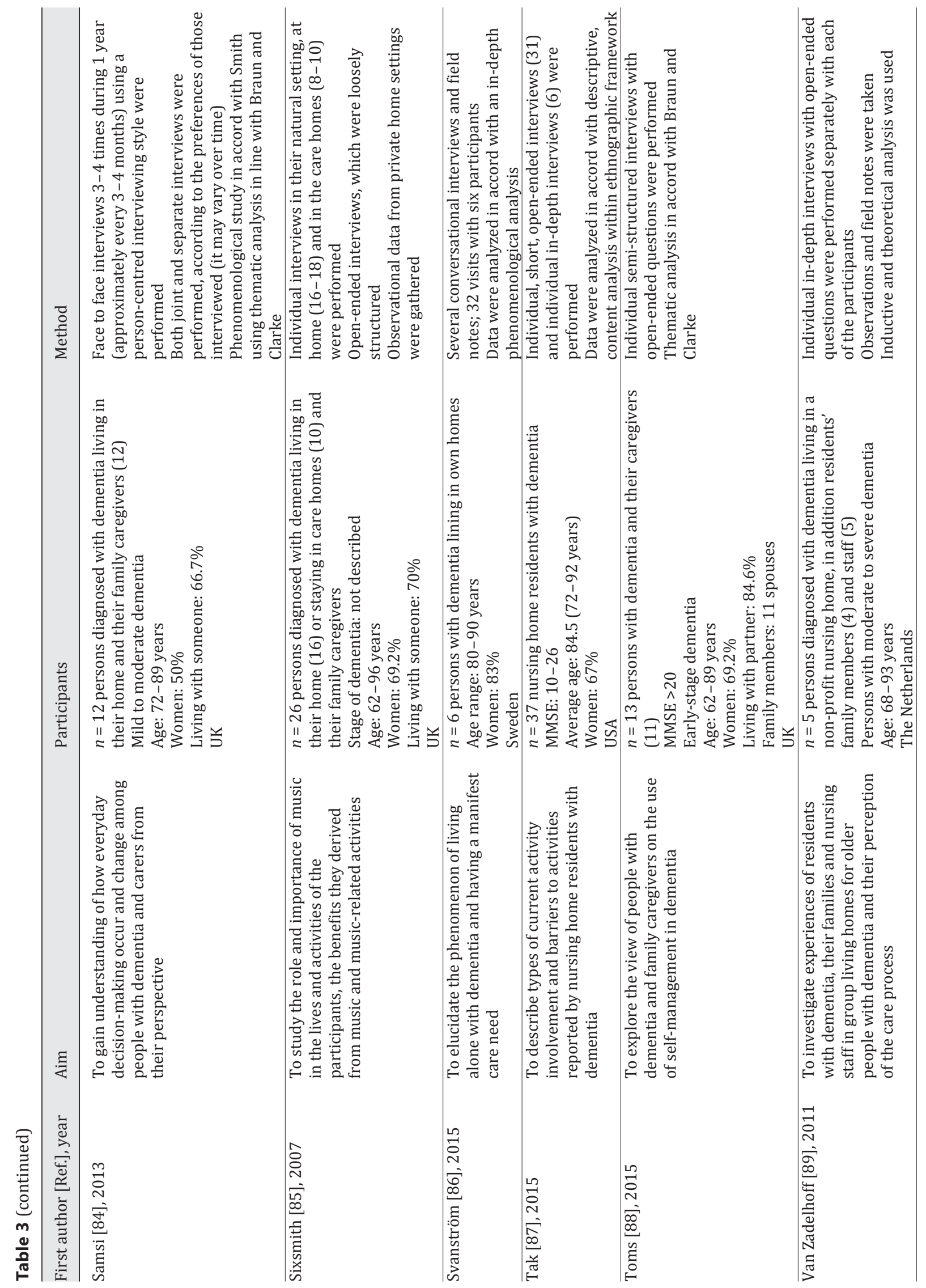


Dementia

Cognitive Disorders
Dement Geriatr Cogn Disord 2016,42:342-368

DOI: $10.1159 / 000452404$

www.karger.com/dem

Eriksen et al.: The Experience of Relations in Persons with Dementia: A Systematic Meta-Synthesis

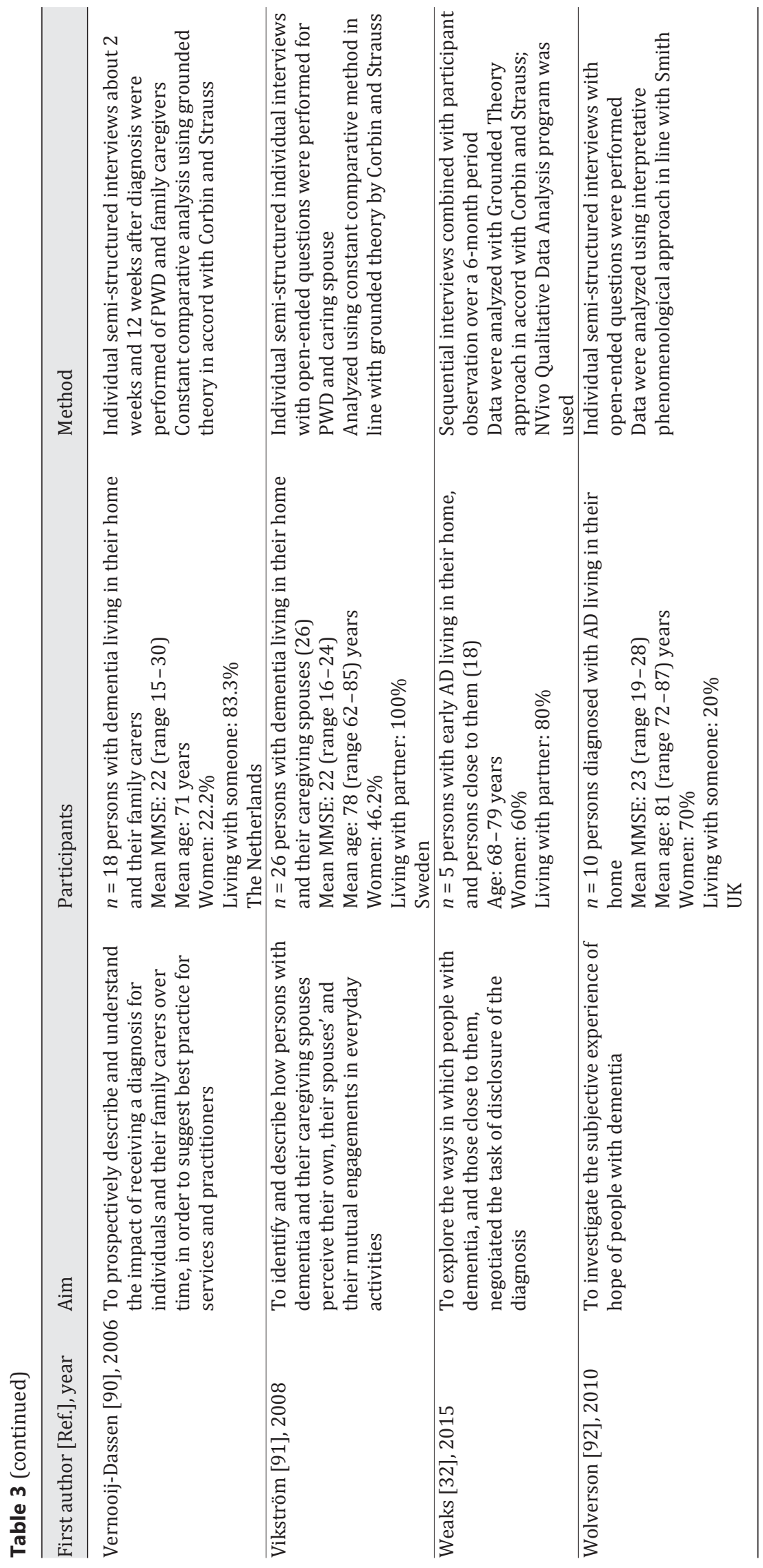


Dementia

Cognitive Disorders
Dement Geriatr Cogn Disord 2016,42:342-368

DOI: 10.1159/000452404

Eriksen et al.: The Experience of Relations in Persons with Dementia: A Systematic Meta-Synthesis

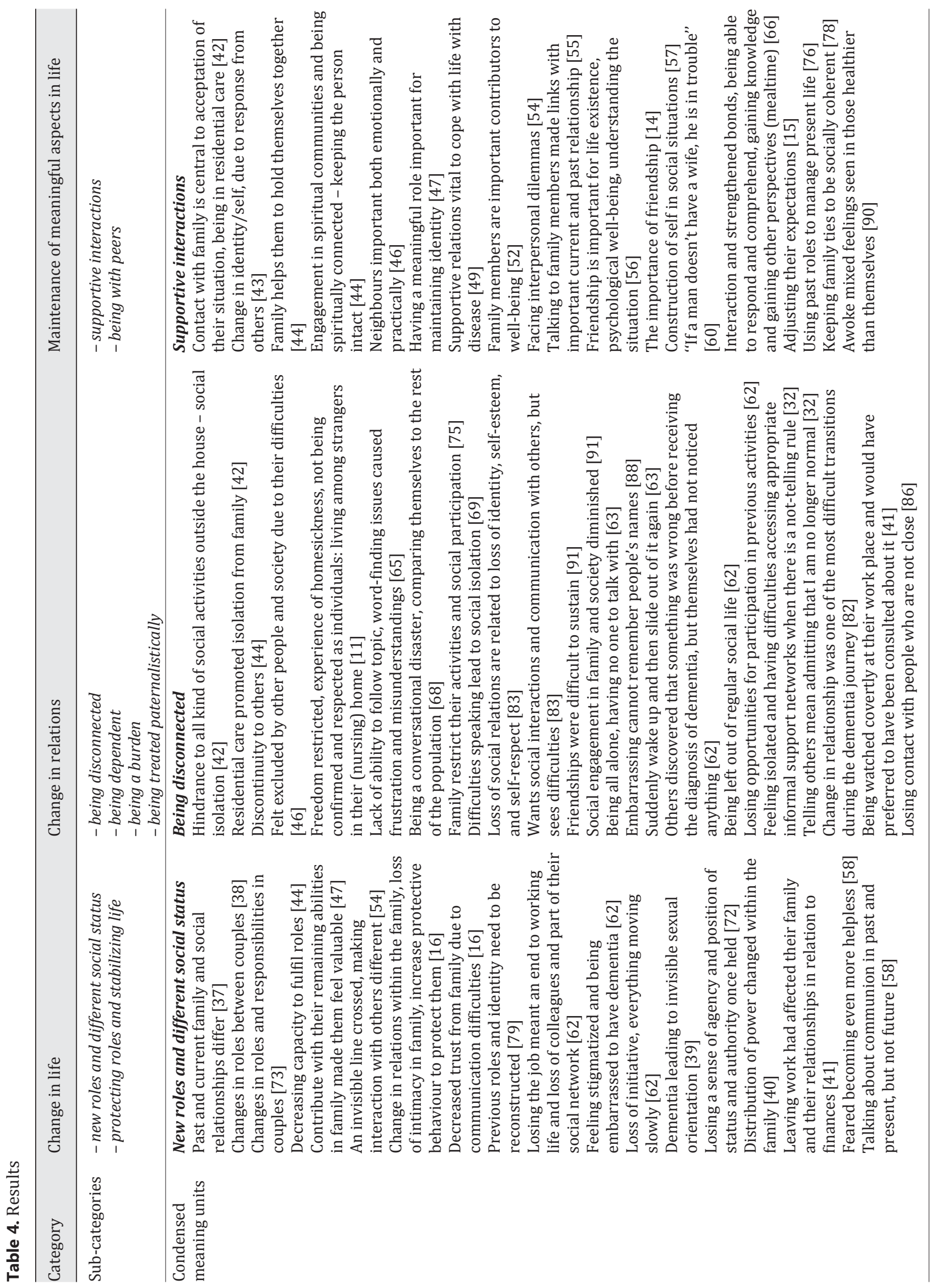


Dementia

and Geriatric
Cognitive Disorders
Dement Geriatr Cogn Disord 2016,42:342-368

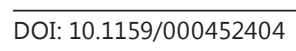

2016 S. Karger AG, Base

www.karger.com/dem

Eriksen et al.: The Experience of Relations in Persons with Dementia: A Systematic Meta-Synthesis

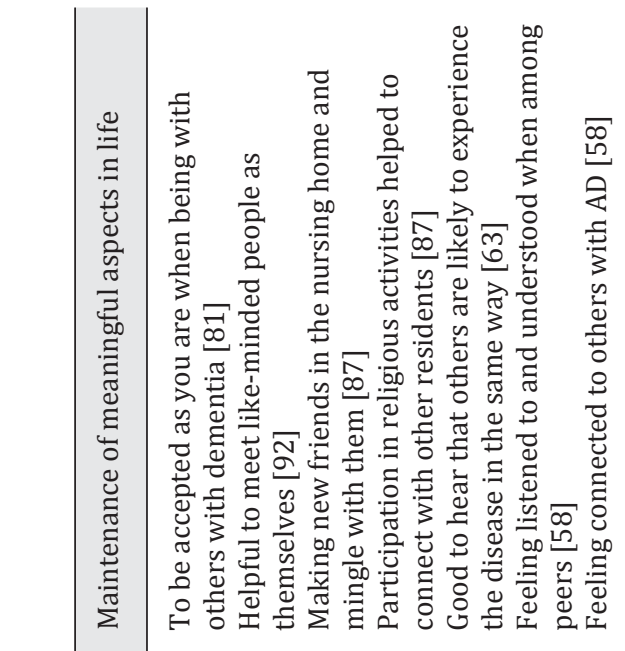

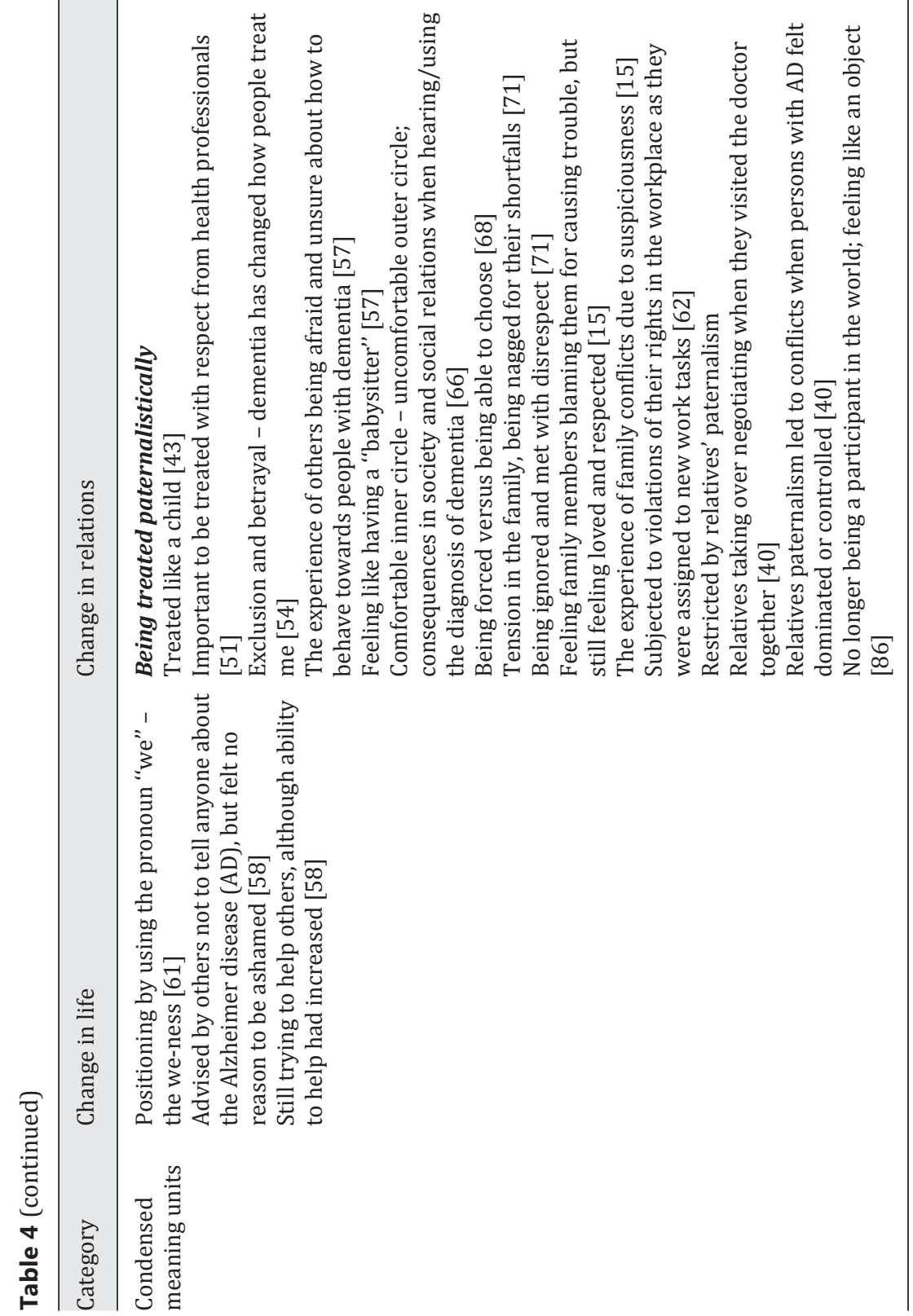


Dementia

and Geriatric

Cognitive Disorders

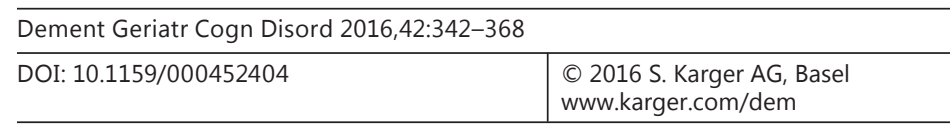

Eriksen et al.: The Experience of Relations in Persons with Dementia: A Systematic Meta-Synthesis

\section{Results}

The analysis revealed three categories: (1) change in life; (2) change in relations; and (3) maintenance of meaningful aspects of life. The categories were further divided into subcategories, which described the extracted meaning from the selected areas highlighted in the included articles, see Table 4.

\section{Change in Life}

This category is differentiated into the following subcategories: (a) new roles and different social status, and (b) protecting roles and stabilizing life. The person's experience of living with dementia was characterized by challenges regarding their roles and social shifts. In addition, the process of adapting to these changes was essential. The adversity of the descriptions presented differs from a position wanting to stop the progression of the impairment to realizing the need for help, accepting the new roles and the changed status, and appreciating the protection and support from family and friends. For the PWD, the social environment and the network represent a stabilizing aspect and help them to avoid thoughts and worries about the possible progression of the disease.

New roles and different social status consist of the declining functional levels that affect the person's position in the family and relations with significant others. In terms of reconstructing roles and identity, the person's experiences of changes in life included the social environment, and the next of kin become more protective than before.

Protecting roles and stabilizing life describe what the person does to compensate for a lack of ability, such as the ability to communicate. The person is trying to normalize the situation and cover up the dementia. Some individuals are trying to spare close relatives from grief.

\section{Change in Relations}

This category is separated into the subcategories: (a) being disconnected, (b) being dependent, (c) being a burden, and (d) being treated. All of these subcategories are incorporated into a state in the PWD. By using the verb 'being', we have interpreted the statements given as an active presentation, as this is how the PWD describes the changes in relations. The presentation highlights how the person experiences himself/herself, based on the reflection from the surroundings.

Being disconnected represents the distance from social relations and known activities. The experience of withdrawal, discontinuity, isolation, restricted freedom, and homesickness (for those living in a nursing home) might be present. The distance could be understood as either wanting to be disconnected from others, or others disconnecting them. People around them might not be able to understand and thereby are not able to reach the PWD, or the PWD may feel like he/she is not being treated as a fellow human being and that their contact is restricted.

Being dependent is a consequence of the functional impairment in activities of daily living and reduced cognitive and social function for the PWD. The PWD might experience loss of adult competence at several levels. Family and friends must take on the function as caregiver when the PWD lacks the ability to continue with his/her daily activities.

Being a burden is expressed as the experience of family and friends struggling with them. PWD experience being a burden and being sensitive to the consequences for their caregivers.

The last subcategory, being treated in paternalistic ways, consists of how family, friends and healthcare personnel behave towards the PWD. Being treated describes care without choices and the ability to influence the action. The approach might be experienced as lack of autonomy, exclusion, betrayal, and a feeling of being treated like a child. 
Eriksen et al.: The Experience of Relations in Persons with Dementia: A Systematic Meta-Synthesis

\section{Maintenance of Meaningful Aspects in Life}

The third category revealed two subcategories: (a) supportive interactions and (b) being with peers. The studies emphasize that both old and new relationships play significant roles in maintaining important aspects of a meaningful life.

Descriptions of the supportive interactions incorporate maintenance in terms of adjusting to the situation and accepting the situation. Family and others might give practical and emotional support, and thereby play an essential role. We have selected a statement from one of the articles that puts into words the essence of the supportive interactions: "Family steer me with invisible wheels" [53]. In addition, friendships, family, and engagement in spiritual communities seem to be particularly important.

Being with peers represents the valuable and meaningful dwelling with others in the same situation. On one hand, the common situation for PWD is interpreted as being part of a group that is engaged in the same activities. Being with peers reduces the experience of isolation, shapes a feeling of being accepted as they are, and thereby supports their identity. On the other hand, the companionship in an institution might be difficult, and some individuals avoid specific patients and staff.

\section{Living a Meaningful Life in Relational Changes}

An overall synthesis of the categories generated from the included articles reveals the comprehensive understanding and the latent meaning expressed as: Living a meaningful life in relational changes. Most of the statements represented a type of relational change. However, the expression of the PWD always seems to incorporate their fulfilment of a meaningful life during the different stages of dementia. The three categories: (1) change in life; (2) change in relations; and (3) maintenance of meaningful aspects in life, all represent the process used by the PWD in terms of shaping their new living situation and their struggle for meaningful relationships in life, despite the dementia-related changes.

\section{Discussion}

The aim of this systematic meta-synthesis was to interpret and synthesize PWD's experiences of lived relations with others. This study shows that relations with others such as family, friends, neighbours, and healthcare personnel are important in the lives of PWD in different ways. The included studies had different perspectives on how social relations might change for individuals with dementia and describe the vulnerable experience of being disconnected from others; being dependent on family, friends, and healthcare personnel; feeling like a burden to close relatives; and being a person who is treated in paternalistic ways. Some of the studies also emphasize the importance of social relationships and what others can do to meet and support the PWD. However, some studies describe that it is important for PWD to protect themselves and describe the efforts they make to stabilize their lives and maintain relationships. Some studies highlight that PWD seem to protect themselves by avoiding challenging social relations.

From the perspective of PWD, the life changes after receiving a diagnosis of dementia involve an altered social status and new social roles. Every person receiving the diagnosis of dementia has a life story, and relations are an essential part of that story. The person is a mother or father, daughter or son, friend, spouse, colleague, and part of a family, a network of friends, and a society, etc. Being in relationships with others is important to our identity and our experience of self. The experience of social relationships is a crucial factor in the quality of life [25]. Relationship with others might give us a sense of security; we feel that we belong to someone, and, in a particular setting, we mean something to other people and we 
Eriksen et al.: The Experience of Relations in Persons with Dementia: A Systematic Meta-Synthesis

have particular roles and tasks. Both van Manen [18] and Ricoeur [26] state that a person's life-world constitutes a dialectic between the past, present, and future. When a story is being told, the past will be brought into the present, and from that point of view, an individual will be looking into the future. From this perspective, the life-world does not only represent the "here and now." The present perception of lived relation with others also has a connection to the past and future.

The phrase living a meaningful life in relational changes describes the essence of the PWD experience of lived relations with others. When close relations change, life will change. When life changes, close relations will change. When an individual has dementia, his/her life will be different in several ways. The present is characterized by uncertainty. A new situation has emerged, changing daily life in different ways. The future is "blurry", and one does not know what to expect or count on, which is not exceptional for PWD. Others experiencing diseases with serious repercussions on their lives, for instance a severe stroke, might describe the same uncertainty about the future. What makes it particularly challenging for many PWD is that there will be parts of their lives that they no longer will remember. The continuity between past, present, and future, the "life line," could be understood as a chain at risk of breaking. How social relations face the changes and adapt to them, can be essential for the PWD's experience. When PWD are no longer capable of maintaining important aspects to live a meaningful life, others might help them do so. Social relations might 'patch up' the gaps by reminding the PWD and maintaining essential aspects from the past, thereby strengthening the chain. The perspective of the life story is an important aspect of a person-centred approach in dementia care by taking into account that the person has been and still is a part of a social context [27-29].

Dementia will change the cognitive capacity and often the physical capability and naturally lead to a decreased ability to perform activities and to participate in different ways. These changes in capabilities often cause changes in the way the surroundings relate to or count on the PWD. PWD might feel stigmatized [30] and are not able to distance themselves from the changes that are occurring. They live with and within the changes and might experience being different in their own and others' eyes. Living with dementia could be considered as a tremendous stress factor in life. The person struggles for a sense of coherence to cope with stress. According to Antonovsky, the sense of coherence consists of three elements: (1) comprehensibility, including predictability and understanding; (2) manageability, including skills and the ability to manage; and (3) meaningfulness, including a belief that things in life are interesting, worthwhile, and that there are good reasons and purposes for things to happen [25, 31]. Additionally, Antonovsky emphasizes the element of meaningfulness as the most important aspect [25]. Our findings show that other persons have an essential impact on the experience of meaning for PWD. Therefore, the changes due to dementia, social relations, and the meaning of life are intertwined aspects. The findings are in accord with the theory of van Manen, highlighting that meaningfulness and the grounds for living are found within the experience of relations with others [18, 31]. Both van Manen and Antonovsky underscore that meaningfulness in life may influence how a person addresses stress. Many PWD postpone telling others about their disease because of the stress and feelings they experience when they receive the diagnosis of dementia. However, one of the most recently published articles highlights the importance of openness and telling others about the diagnosis, which might give hope for a more transparent society [32].

Studies have shown that the numbers of social connections are less important than how the person experiences the quality of the relationships $[6,33,34]$. Therefore, one has to be aware of the fact that not every relation is a good relation. Good relationships could be a buffer against symptoms of anxiety and depression. Poor relationships might have the opposite effect. Relational meaningfulness might be a stabilizer, shaping continuity and 
Eriksen et al.: The Experience of Relations in Persons with Dementia: A Systematic Meta-Synthesis

protecting against expressions such as agitation [35]. Several studies emphasized the aspect of being with others with dementia, which could be an expression of equality, comfort or safety. When they are with others with dementia, PWD are not supposed to be more or perform more than they are capable of doing. PWD feel accepted as they are and are listened to and understood.

\section{Implications for Practice}

Family and healthcare personnel have to be aware of their important roles as supportive persons, enabling PWD to continue living a meaningful life. Understanding and accepting the cognitive changes in a family member or a friend suffering from dementia could be difficult and is a continuous process along with the progression of the disease. There is a need for information, education and counselling of family and friends, as well as health personnel. Emancipation and person centeredness should be the key concepts guiding the care provided to sustain the PWD's feelings of still being involved in their own life in the present and also in the future.

\section{Strengths and Limitations}

We have performed a systematic meta-synthesis with transparent descriptions of the selection process for the included articles. However, we acknowledge that a completed overview is not attainable, despite our approaches. The value of both individual reviewers and the use of pairs of researchers to evaluate the studies has to be accredited.

\section{Conclusions}

This systematic meta-synthesis shows that relations with others are important in the lives of PWD. The three categories revealed from the 63 articles, change in life, change in relations, and maintenance of meaningful aspects in life, are intertwined and essential for sustaining the lifeline for PWD. The comprehensive meaning is understood as the expression: Living a meaningful life in relational changes.

\section{Acknowledgement}

We thank university librarian Marit Gjone Sandsleth for providing essential help and advice on the computer-aided search, and Professor Emeritus Knut Engedal for his valuable comments on the preparation of the manuscript.

\section{Disclosure Statement}

The authors declare that they have no conflicts of interest. 
Eriksen et al.: The Experience of Relations in Persons with Dementia: A Systematic Meta-Synthesis

\section{References}

3 Crooks V, Lubben J, Petitti D, Little D, Chiu V: Social network, cognitive function, and dementia incidence among elderly women. Am J Public Health 2008;98:1221-1227.

4 Ryff C, Singer B, Love G: Positive health: connecting well-being with biology. Philos Trans R Soc Lond B 2004; 359:1383-1394.

5 Friedman E, Karlamangla A, Almeida D, Seeman T: Social strain and cortisol regulation in midlife in the US. Soc Sci Med 2012;74:607-615.

6 Krause N: Longitudinal study of social support and meaning of life. Psychol Aging 2007;22:456-469.

7 Tranvåg 0, Petersen K, Nåden D: Dignity-preserving dementia care: a metasynthesis. Nurs Ethics 2013;20: 861-880.

8 Steeman E, De Casterlé B, Godderis J, Grypdonck M: Living with early stage dementia: a review of qualitative studies. J Adv Nurs 2006;54:722-738.

9 Strech D, Mertz M, Knüppel H, Neitzke G, Schmidhuber M: The full spectrum of ethical issues in dementia care: systematic qualitative review. Br J Psychiatry 2013;402:400-406.

10 Qazi A, Spector A, Orrell M: User, carer and staff perspectives on anxiety in dementia: a qualitative study. J Affect Disord 2010;125:295-300.

11 Heggestad AK, Nortvedt P, Slettebo A: "Like a prison without bars": dementia and experiences of dignity. Nurs Ethics 2013;20:881-892.

12 Tranvåg 0, Petersen K, Nåden D: Relational interactions preserving dignity experience. Nurs Ethics 2015;22: 577-593.

13 Derksen E, Vernooij-Dassen M, Gillissen F, Rikkert MO, Scheltens P: Impact of diagnostic disclosure in dementia on patients and carers: qualitative case series analysis. Aging Ment Health 2006;10:525-531.

14 Harris PB: Dementia and friendship: the quality and nature of the relationships that remain. Int J Aging Hum Dev 2013;76:141-164

15 Mazaheri M, Eriksson LE, Nasrabadi AN, Sunvisson H, Heikkila K: Experiences of dementia in a foreign country: qualitative content analysis of interviews with people with dementia. BMC Public Health 2014;14:794.

16 Mok E, Lai CK, Wong FL, Wan P: Living with early-stage dementia: the perspective of older Chinese people. J Adv Nurs 2007;59:591-600.

17 Benner P, Wrubel J: Primacy of Caring Stress and Coping in Health and Illness. Menlo Park, Addison-Wesley, 1989.

18 van Manen M (ed): Researching Lived Experience. Human Science for an Action Sensitive Pedagogy, ed 2. London, Althouse Press, 1997, pp 202.

19 Paterson B, Thorne S, Canam C, Jillings C: Meta-Study of Qualitative Health Research: A Practical Guide to MetaAnalysis and Meta-Synthesis. Thousand Oaks, Sage Publications, 2001.

20 Zimmer L: Qualitative meta-synthesis: a question of dialoguing with texts. J Adv Nurs 2006;53:311-318.

21 Shamseer L, Moher D, Clarke M, Ghersi D, Liberati A, Petticrew M, Shekelle P, Stewart L: Preferred reporting items for systematic review and meta-analysis protocols (PRISMA-P) 2015: elaboration and explanation. BM) 2015;349:g7647.

22 Dixon-Woods M, Agarwal S, Jones D, Young B, Sutton A: Synthesising qualitative and quantitative evidence: a review of possible methods. J Health Serv Res Policy 2005;10:45-53.

23 Eilertsen G, Ormstad H, Kirkevold M: Experiences of poststroke fatigue: a qualitative meta-synthesis. J Adv Nurs 2013;69:514-525.

24 Graneheim U, Lundman B: Qualitative content analysis in nursing research: concepts, procedures and measures to achieve trustworthiness. Nurse Educ Today 2004;24:105-112.

25 Eriksson M, Lindstrøm B: Anonovsky's sense of coherence scale and its relation with quality of life: a systematic review. J Epidemiol Community Health 2007;61:938-944.

26 Ricoeur P: Creativity of language; in Kearney R (ed): States of Mind: Dialogues with Contemporary Thinkers on the European Mind. Manchester, Manchester University Press, 1995.

27 Kitwood T: Dementia Reconsidered: The Person Comes First. Buckingham, Open University Press, 1997.

28 Edvardsson D, Petersson L, Sjogren K, Lindkvist M, Sandman P: Everyday activities for people with dementia in residential aged care: associations with person-centredness and quality of life. Int J Older People Nurs 2014 ; 9:269-276.

29 McCance T, McCormack B, Dewing J: An exploration of person-centredness in practice. Online J Issues Nurs 2011;16:1.

30 Goffman E: Stigma. Hamondsworth, Penguin, 1963.

31 Antonovsky A: Health, Stress and Coping. San Francisco, Jossey-Bass, 1979

32 Weaks DOT, Wilkinson H, McLeod J: Daring to tell: the importance of telling others about a diagnosis of dementia. Ageing Soc 2015;35:765-784.

33 Shim B, Barroso J, Davis L: A comparative analysis of stories of spousal categivers of people with dementia: negative, ambivalent, and positive experiences. Int J Nurs Stud 2012;49:220-229.

34 Shim B, Barroso J, Gilliss C, Davis L: Finding meaning in caring for a spouse with dementia. Appl Nurs Res 2013; 26:121-126. 
Eriksen et al.: The Experience of Relations in Persons with Dementia: A Systematic Meta-Synthesis

35 Cohen-Mansfield J, Dakheel-Ali M, Marx M, Thein K, Regier N: Which unmet needs contribute to behavior problems in persons with advanced dementia? Psychiatry Res 2015;228:59-64.

36 Aminzadeh F, Dalziel WB, Molnar FJ, Garcia LJ: Symbolic meaning of relocation to a residential care facility for persons with dementia. Aging Ment Health 2009;13:487-496.

37 Aminzadeh F, Dalziel WB, Molnar FJ, Garcia LJ: Meanings, functions, and experiences of living at home for individuals with dementia at the critical point of relocation. J Gerontol Nurs 2010;36:28-35; quiz 36-27.

38 Atta-Konadu E, Keller HH, Daly K: The food-related role shift experiences of spousal male care partners and their wives with dementia. J Aging Stud 2011;25:305-315.

39 Barrett C, Crameri P, Lambourne S, Latham JR, Whyte C: Understanding the experiences and needs of lesbian, gay, bisexual and trans Australians living with dementia, and their partners. Australas J Ageing 2015;34: 34-38.

40 Bronner K, Perneczky R, McCabe R, Kurz A, Hamann J: Which medical and social decision topics are important after early diagnosis of Alzheimer's disease from the perspectives of people with Alzheimer's disease, spouses and professionals? BMC Res Notes 2016;9:149.

41 Chaplin R, Davidson I: What are the experiences of people with dementia in employment? Dementia 2016;15: 147-161.

42 Clare L, Rowlands J, Bruce E, Surr C, Downs M: The experience of living with dementia in residential care: an interpretive phenomenological analysis. Gerontologist 2008;48:711-720.

43 Clemerson G, Walsh S, Isaac C: Towards living well with young onset dementia: an exploration of coping from the perspective of those diagnosed. Dementia 2014;13:451-466.

44 Dalby P, Sperlinger DJ, Boddington S: The lived experience of spirituality and dementia in older people living with mild to moderate dementia. Dementia 2012;11:75-94.

45 Fleming R, Kelly F, Stillfried G: "I want to feel at home": establishing what aspects of environmental design are important to people with dementia nearing the end of life. BMC Palliat Care 2015;14:26.

46 Frazer SM, Oyebode JR, Cleary A: How older women who live alone with dementia make sense of their experiences: an interpretative phenomenological analysis. Dementia 2012;11:677-693.

47 Genoe R, Dupuis SL, Keller HH, Martin LS, Cassolato C, Edward HG: Honouring identity through mealtimes in families living with dementia. J Aging Stud 2010;24:181-193.

48 Genoe MR, Keller HH, Martin LS, Dupuis SL, Reimer H, Cassolato C, Edward G: Adjusting to mealtime change within the context of dementia. Can J Aging 2012;31:173-194.

49 Genoe MR, Dupuis SL: The role of leisure within the dementia context. Dementia 2014;13:33-58.

50 Gill L, White L, Cameron ID: Interaction in community-based aged healthcare: perceptions of people with dementia. Dementia 2011;10:539-554.

51 Gilmour JA, Huntington AD: Finding the balance: living with memory loss. Int J Nurs Pract 2005;11:118-124

52 Goodman C, Amador S, Elmore N, Machen I, Mathie E: Preferences and priorities for ongoing and end-of-life care: a qualitative study of older people with dementia resident in care homes. Int J Nurs Stud 2013;50:16391647.

53 Hain D, Touhy TA, Compton Sparks D, Engström G: Using narratives of individuals and couples living with early stage dementia to guide practice. J Nurs Pract Appl Rev Res 2014;4:82-93.

54 Harman G, Clare L: Illness representations and lived experience in early-stage dementia. Qual Health Res 2006;16:484-502.

55 Harmer BJ, Orrell M: What is meaningful activity for people with dementia living in care homes? A comparison of the views of older people with dementia, staff and family carers. Aging Ment Health 2008;12:548-558.

56 Harris SM, Adams MS, Zubatsky M, White M: A caregiver perspective of how Alzheimer's disease and related disorders affect couple intimacy. Aging Ment Health 2011;15:950-960.

57 Hedman R, Hansebo G, Ternestedt B-M, Hellström I, Norberg A: How people with Alzheimer's disease express their sense of self: analysis using Rom Harré's theory of selfhood. Dementia 2013;12:713-733.

58 Hedman R, Hansebo G, Ternestedt BM, Hellstrom I, Norberg A: Expressed sense of self by people with Alzheimer's disease in a support group interpreted in terms of agency and communion. J Appl Gerontol 2016; 35:421-443.

59 Hellstrom I, Eriksson H, Sandberg J: Chores and sense of self: gendered understandings of voices of older married women with dementia. Int J Older People Nurs 2015;10:127-135.

60 Hulko W: From "not a big deal" to "hellish": experiences of older people with dementia. J Aging Stud 2009;23: 131-144.

61 Hydén L-C, Nilsson E: Couples with dementia: positioning the “we.” Dementia 2015;14:716-733.

62 Johannessen A, Möller A: Experiences of persons with early-onset dementia in everyday life: a qualitative study. Dementia 2011;12:410-424.

63 Johannessen A, Moller A, Haugen PK, Biong S: A shifting sense of being: a secondary analysis and comparison of two qualitative studies on young-onset dementia. Int J Qual Stud Health Well-being 2014;9:24756.

64 Karlsson E, Sävenstedt S, Axelsson K, Zingmark K: Stories about life narrated by people with Alzheimer's disease. J Adv Nurs 2014;70:2791-2799.

65 Keller HH, Martin LS, Dupuis S, Genoe R, Edward HG, Cassolato C: Mealtimes and being connected in the community-based dementia context. Dementia 2010;9:191-213.

66 Langdon SA, Eagle A, Warner J: Making sense of dementia in the social world: a qualitative study. Soc Sci Med 2007;64:989-1000. 
Eriksen et al.: The Experience of Relations in Persons with Dementia: A Systematic Meta-Synthesis

67 Lawrence V, Murray J, Ffytche D, Banerjee S: “Out of sight, out of mind”: a qualitative study of visual impairment and dementia from three perspectives. Int Psychogeriatr 2009;21:511-518.

68 Lee SM, Roen K, Thornton A: The psychological impact of a diagnosis of Alzheimer's disease. Dementia 2014; 13:289-305.

69 MacKinlay E: Using spiritual reminiscence with a small group of Latvian residents with dementia in a nursing home: a multifaith and multicultural perspective. J Relig Spiritual Aging 2009;21:318-329.

70 MacRae H: Self and other: the importance of social interaction and social relationships in shaping the experience of early-stage Alzheimer's disease. J Aging Stud 2011;25:445-456.

71 Mazaheri M, Eriksson LE, Heikkilä K, Nasrabadi AN, Ekman S-L, Sunvisson H: Experiences of living with dementia: qualitative content analysis of semi-structured interviews. J Clin Nurs 2013;22:3032-3041.

72 Merrick K, Camic PM, O'Shaughnessy M: Couples constructing their experiences of dementia: a relational perspective. Dementia 2016;15:34-50.

73 Molyneaux VJ, Butchard S, Simpson J, Murray C: The co-construction of couplehood in dementia. Dementia 2012;11:483-502.

74 Moyle W, Venturto L, Griffiths S, Grimbeek P, McAllister M, Oxlade D, Murfield J: Factors influencing quality of life for people with dementia: a qualitative perspective. Aging Ment Health 2011;15:970-977.

75 Mushi D, Rongai A, Paddick SM, Dotchin C, Mtuya C, Walker R: Social representation and practices related to dementia in Hai District of Tanzania. BMC Public Health 2014;14:260.

76 Nowell ZC, Thornton A, Simpson J: The subjective experience of personhood in dementia care settings. Dementia 2013;12:394-409.

77 Nygard L: Meaning of everyday technology as experienced by people with dementia who live alone. Dementia 2008; 7:481-502.

78 Ohman A, Nygard L: Meanings and motives for engagement in self-chosen daily life occupations among individuals with Alzheimer's disease. OTJR 2005;25:89-97.

79 Pesonen HM, Remes AM, Isola A: Diagnosis of dementia as a turning point among Finnish families: a qualitative study. Nurs Health Sci 2013;15:489-496.

80 Phinney A: Family strategies for supporting involvement in meaningful activity by persons with dementia. J Fam Nurs 2006;12:80-101.

81 Pipon-Young FE, Lee KM, Jones F, Guss R: I'm not all gone, I can still speak: the experiences of younger people with dementia. An action research study. Dementia 2012;11:597-616.

82 Roach P, Drummond N, Keady J: "Nobody would say that it is Alzheimer's or dementia at this age": family adjustment following a diagnosis of early-onset dementia. J Aging Stud 2016;36:26-32.

83 Rostad D, Hellzen 0, Enmarker I: The meaning of being young with dementia and living at home. Nurs Rep 2013;3:12-17.

84 Samsi K, Manthorpe J: Everyday decision-making in dementia: findings from a longitudinal interview study of people with dementia and family carers. Int Psychogeriatr 2013;25:949-961.

85 Sixsmith A, Gibson G: Music and the wellbeing of people with dementia. Ageing Soc 2007;27:127-145.

86 Svanstrom R, Sundler AJ: Gradually losing one's foothold: a fragmented existence when living alone with dementia. Dementia 2015;14:145-163.

87 Tak SH, Kedia S, Tongumpun TM, Hong SH: Activity engagement: perspectives from nursing home residents with dementia. Educ Gerontol 2015;41:182-192.

88 Toms GR, Quinn C, Anderson DE, Clare L: Help yourself: perspectives on self-management from people with dementia and their caregivers. Qual Health Res 2015;25:87-98.

89 van Zadelhoff E, Verbeek H, Widdershoven G, van Rossum E, Abma T: Good care in group home living for people with dementia. Experiences of residents, family and nursing staff. J Clin Nurs 2011;20:2490-2500.

90 Vernooij-Dassen M, Derksen E, Scheltens P, Moniz-Cook E: Receiving a diagnosis of dementia: the experience over time. Dementia 2006;5:397-410.

91 Vikstrom S, Josephsson S, Stigsdotter-Neely A, Nygard L: Engagement in activities: experiences of persons with dementia and their caregiving spouses. Dementia 2008;7:251-270.

92 Wolverson EL, Clarke C, Moniz-Cook E: Remaining hopeful in early-stage dementia: a qualitative study. Aging Ment Health 2010;14:450-460. 